\title{
Osteoporoz Riskinin Değerlendirilmesi
}

\section{Osteoporosis Risk Assessment}

\author{
Ali IPEK, Ümit GAFUROĞLU, Hatice BODUR, Özlem YILMAZ \\ Ankara Numune Eğitim ve Araştırma Hastanesi, Fiziksel Tıp ve Rehabilitasyon Kliniği, Ankara, Türkiye
}

\section{Özet}

Amaç: Bu çalışmanın amacı maliyetleri en aza indirmek için osteoporoz risk indekslerini kullanarak kemik mineral yoğunluğu (KMY) ölçümünde hangi hastalara öncelik verileceğini belirlemektir.

Gereç ve Yöntem: Çalışmaya 45 yaş ve üzeri 537 postmenopozal kadın alındı. L1-L4 vertebra ve femur boynu KMY'leri Dual Enerji X-Ray Absorpsiyometri yöntemiyle ölçüldü. Osteoporoz Tarama Aracı (Osteoporosis Screening Tool-OST), Basit Hesaplanan Osteoporoz Risk Tahmini (Simple Calculated Osteoporosis Risk Estimation-SCORE), Osteoporoz Risk Değerlendirme Aracı (Osteoporosis Risk Assessment Instrument-ORAI), Osteoporoz Risk Indeksi (Osteoporosis Index of RiskOSIRIS) indeksleri ve Dünya Sağlık Örgütü Kırık Riski Değerlendirme Aracı (WHO Fracture Risk Assessment Tool-FRAX) algoritması uygulandı. KMY'si düşük olguları ayırdetmede tahmin değeri en yüksek olan risk indekslerini saptamak amacıyla, indekslerin duyarlılık, seçicilik, pozitif ve negatif tahmin değerleri (PTD ve NTD) araştırıldı.

Bulgular: Olguların \%34,3'ünde osteoporoz saptandı. Tüm indekslerde, yüksek risk gruplarında osteoporoz oranı daha yüksekti. Bu çalışmada duyarlıık, seçicilik, PTD ve NTD yönünden en etkili indeksler OST, SCORE ve FRAX-H olarak izlendi. Ancak lomber bölgede, indeksler ile gözden kaçabilecek hasta oranı yeterince düşük bulunmadı.

Sonuç: Lomber bölgede gözden kaçabilecek hasta oranını azaltabilmek için eşik değerlerin yeniden belirlenmesi gerekebilir. Bu yönde çalışmalar gereklidir. Ancak osteoporozda major morbidite ve mortalitenin kalça osteoporozu ve kırıklarına bağlı olduğu düşünülürse bu testlerin tarama testi olarak yararlı olacağı ileri sürülebilir. Türk Fiz Tıp Rehab Derg 2012;58:212-19

Anahtar Kelimeler: Postmenopozal osteoporoz; risk indeksi

\section{Summary}

Objective: The aim of this study was to determine which patients have priority for Bone Mineral Density (BMD) measurement by using osteoporosis risk indices in order to reduce diagnostic costs.

Metarials and Methods: BMD at the lumbar spine (L1-L4) and the femur neck was measured using Dual Energy X-Ray absorptiometry in 537 postmenopausal women aged 45 years or older. Risk indices like Osteoporosis Screening Tool (OST), Simple Calculated Osteoporosis Risk Estimation (SCORE), Osteoporosis Risk Assessment Instrument (ORAl), Osteoporosis Index of Risk (OSIRIS) and the WHO Fracture Risk Assessment Tool (FRAX) scores were calculated. Sensitivity, selectivity, positive and negative predictive values of the indexes was investigated to detect patients with low BMD.

Results: Osteoporosis was observed in $34,3 \%$ of the subjects. Osteoporosis rate was found to be high in high-risk groups of all indexes. The most effective indices were observed to be OST, SCORE and FRAX-H, in terms of sensitivity, selectivity, positive and negative predicting value. However, in the lumbar region, ratio of patients that can be missed using indexes was not found low enough.

Conclusion: In this study, the most effective indices were observed to be OST, SCORE and FRAX-H. The rate of overlooked patients was not low enough in the lumbar area. We believe that, it would be useful to use screening tests for femur osteoporosis. Turk J Phys Med Rehab 2012;58:212-19.

Key Words: Post-menopausal osteoporosis; risk index

Yazışma Adresi/Address for Correspondence: Dr. Ümit Gafuroğlu, Ankara Numune Eğitim ve Araştırma Hastanesi, Fizik Tedavi ve Rehabilitasyon Kliniği, Ankara, Türkiye Tel.: +90 3125084802 E-posta: umitseckin@gmail.com 


\section{Giriş}

Osteoporoz (OP), kemik kütlesinde azalma ve kemik kırılganlığında artış ile seyreden metabolik bir kemik hastalığıdır. İnsan ömrünün uzaması ile birlikte görülme sıklığı artan osteoporoz, günümüzde önemli bir halk sağlığı sorunu haline gelmiştir. Özellikle kalça kırıkları artmış morbidite ve mortalite ile sonuçlanmaktadır. Osteoporoz yüksek maliyetli bir hastalıktır. Hastanede kalınan günler anlamında osteoporoz, sağlık sistemleri üzerinde kronik obstrüktif akciğer hastalığı, inme, myokard infarktüsü ve meme kanseri gibi pek çok majör hastalığa göre daha fazla maliyet yükü oluşturur. Avrupa Birliği'nde vergi mükellefleri tarafından osteoporoza bağlı kalça kırıklarını tedavi etmek için ödenen yıllık hastane sağlık-bakım masraflarının yaklaşık 4,8 milyar $€$ olduğu hesaplanmıştır (1).

$\mathrm{Bu}$ önemli hastalığın erken teşhis edilmesi, olası komplikasyonların önlenebilmesi ve tedavisi için gereklidir. Osteoporozda Kemik Mineral Yoğunluğu (KMY) ölçümü çok önemli bir tanısal parametredir. KMY ölçümünde bugün için Dual Enerji X-Ray Absorpsiyometri (DXA) yöntemi altın standart olarak kabul edilmektedir. DXA kırık oluşmadan önce osteoporoz ve/veya osteopeniyi saptar. Tekrarlanan ölçümlerle kemik kaybının hızını belirler, tedavinin etkinliği ya da başarısızlığı hakkında bilgi verir (2). Ancak DXA tetkikinin bir maliyeti olduğu ve ulaşmanın kolay olmadığı açıktır. Gelişmekte olan bazı ülkelerde hatta bazı Avrupa ülkelerinde bile yaygın olarak bulunmamakta ya da geri ödeme problemleri nedeniyle ulusal sağlık kuruluşları tarafından yaygın olarak kullanımı kısıtlanmaktadır. Bu noktadan yola çıkarak düşük KMY'ye sahip hastaları klinik olarak saptamak amacı ile major risk faktörlerinin sorgulandığı risk değerlendirme indeksleri geliştirilmistir.

Bu çalışmanın amacl; KMY ölçümünün getirdiği gereksiz maliyet, iş gücü kaybı, zaman kaybı ve hastane yoğunluğu gibi olumsuzlukları azaltmak için; postmenopozal kadınlarda osteoporoz risk indekslerinden Osteoporoz Tarama Aracı (Osteoporosis Screening Tool-OST), Basit Hesaplanan Osteoporoz Risk Tahmini (Simple Calculated Osteoporosis Risk Estimation-SCORE), Osteoporoz Risk Değerlendirme Aracı, (Osteoporosis Risk Assessment Instrument-ORAl), Osteoporoz Risk İndeksi (Osteoporosis Index of Risk-OSIRIS) ve Dünya Sağlık Örgütü Kırık Risk Değerlendirme Aracı (WHO Fracture Risk Assessment Tool-FRAX) algoritmasının performanslarını karşılaştırarak, DXA ölçümüne hangi hastaların gönderilmesi gerektiğini saptamaktır.

\section{Gereç ve Yöntem}

Çalışmaya, radyoloji bölümüne DXA tetkiki için gönderilen 1000 hastadan görüşmeler sonucunda, belirlenen kriterlere uyan 45 yaş ve üzeri 537 postmenopozal kadın dahil edildi. Hastaların 122 'si 65 yaş ve üzerinde idi.

Tüm hastaların hastane bilgi işlem sistemindeki kayıtları incelendi. Romatoid Artrit (RA) dışında sekonder osteoporoza yol açacak; endokrin bozukluklar, gastrointestinal bozukluklar, renal bozukluklar, hemipleji, malignite gibi kemik metabolizmasını etkileyen diğer hastalığı olduğunu ifade edenler, antikonvülzan, antikoagulan, tiroid ekstresi, immünsüpresifler gibi ilaç kullananlar, 45 yaşından önce menopoza girenler, daha önce östrojen dışında osteoporoz tedavisi alanlar çalışma kapsamı dışında bırakıldı.
Katılımcıların KMY ölçümleri Hologic marka Discovery QDR series (140kV 5mA 8337/T03044) model cihaz ile yapıldı. DXA sonuçları; L1-L4 vertebra total T-skoru ve femur boynu T-skoru olarak kayıt edildi. Dünya Sağlık Örgütü sınflamasına göre hastalar T-skoru -2,5 ve altında olanlar osteoporotik, -1 ile -2,5 arasında olanlar osteopenik ve -1 'in üzeri olanlar normal olmak üzere üç gruba ayrıldı (3). Hastaların yaşı, menopoz yaşı, menarş yaşı, medeni durumu, eğitim düzeyi, doğum sayısı, sigara ve alkol kullanımı, kırık ve RA öyküsü, östrojen kullanımı ve steroid kullanımları sorgulandı. Ağırlıkları $\mathrm{kg}$, boyları $\mathrm{cm}$ cinsinden kaydedildi. Vücut kitle indeksleri $\left(\mathrm{kg} / \mathrm{m}^{2}\right)$ hesaplandı. Bu veriler yardımı ile osteoporoz risk indekslerinden; OST (4), SCORE (5), ORAI (6) OSIRIS (7) kullanılarak risk skorları hesaplandı. Eşik değerler; OST, SCORE, ORAI ve OSIRIS için sırasıyla $<2,>7,>8$ ve $<1$ kabul edildi. Hastalar düşük, orta ve yüksek risk grubunda olacak şekilde üç kategoride gruplandırıldı (Tablo 2).

Ayrıca hastalara 10 yıllık mutlak kırık riskini değerlendiren web tabanlı bir algoritma olan http://www.shef.ac.uk/FRAX adresindeki Türkiye için adapte edilmiş (FRAX) algoritması uygulandı (8). Bu şekilde femur boynu T-skoru değeri girilerek ve girilmeden, majör osteoporotik kırık riski ve kalça kırık riski olmak üzere 4 ayrı skor elde edildi. (FRAX T-M: DXA'lı major kırık riski, FRAX T-H: DXA'lı kalça kırık riski, FRAX-M: DXA'sız major kırık riski, FRAX-H: DXA'sız kalça kırık riski (Şekil 1).

\section{Istatistiksel Analizler}

Tanımlayıcı istatistikler sürekli sayısal değişkenler için ortalama standart sapma olarak, kategorik değişkenler ise olgu sayısı ve (\%) biçiminde ifade edildi. İstatistiksel analizler için SPSS for Windows 11.5 paket programı kullanıldı.

Risk indekslerinin ve FRAX'ın, DXA yöntemi ile $\mathrm{L}_{1}-\mathrm{L}_{4}$ vertebra ve femur boynunda osteporoz (T-skor $\leq-2,5$ ) saptamadaki performansları değerlendirildi. Risk indekslerinin iç geçerlilikleri için duyarlıık ve özgüllükleri saptandı. Ayrıca her bir risk indeksinin dış geçerliğini saptamak amacı ile Pozitif Tahmin Değeri (PTD) ve Negatif Tahmin Değeri (NTD) hesaplandı. KMY'si düşük olguları ayırt etmede tahmin değeri en yüksek olan risk indekslerini tespit etmek amacıyla çoklu değişkenli lojistik regresyon analizi kullanıldı. Her bir risk indeksine ait odds oranı, \%95 güven aralığı ve Wald istatistikleri hesaplandı. Lojistik regresyon analizlerinde "enter" yöntemi kullanıldı ve bütün tarama testleri bir arada değerlendirildi. Wald istatistiği en yüksek olan risk indeksi, düşük KMY'li olguları diğer olgulardan ayırt etmede en fazla belirleyiciliği olan risk indeksi olarak kabul edildi.

FRAX algoritmasının KMY parametresi olmayan versiyonu kullanıldı.

\section{Bulgular}

Çalışmaya katılan olguların demografik özellikleri incelendiğinde; yaş ortalamasının $59,5 \pm 8,6$ yıl (46-87), boy ortalamasının $153,9 \pm 6,5 \mathrm{~cm} \quad(135-178)$, vücut ağırlığı ortalamasının $71,4 \pm 12,0$ kg (38-108) olduğu belirlenmiştir. Vücut kitle indeksi ortalaması $30,1 \pm 4,8 \mathrm{~kg} / \mathrm{m}^{2}(18,1-43,3)$ olarak hesaplanmıştır. Olguların menopoz yaşı ortalamasının 49,0 03,4 yıl (45-60), menopoz süresi ortalamasının ise $13,8 \pm 1,4$ yıl (1-37) olduğu görülmüştür. Olguların $\% 8,9^{\prime} u$ östrojen tedavisi almaktaydı. \%2,6'sında RA olduğu, \%9,9'unda ise düşük şiddetli kırık öyküsü olduğu belirlendi (Tablo 1). 
Olguların KMY ölçümlerine göre dağılımlarında; L1-L4 vertebrada olguların \%44,1'inde osteopeni, \%31,8'inde osteoporoz, femur boynunda ise $\% 48,8^{\prime}$ inde osteopeni, \%11'inde ise osteoporoz saptandı. Genel olarak bakıldığında ise hastaların \%47,1'inde en az bir bölgede osteopeni, \%34,3'ünde ise en az bir bölgede osteoporoz mevcuttu (Tablo 3).

Indekslerin risk kategorilerine göre osteoporoz sıklığı değerlendirildiğinde, OST ile hastaların \%67,4'ünde düşük, $\% 27,4$ 'ünde orta ve $\% 5,2$ 'sinde yüksek risk belirlendi. Düşük orta ve yüksek risk grupların KMY ile osteoporoz oranları ise sırasıyla $\% 21, \% 56,5$ ve $\% 89,3$ idi. SCORE ile hastaların $\% 54,4$ ünde düşük, \%40'ında orta ve \%5,6'sında yüksek risk belirlendi. Düşük orta ve yüksek risk grupların KMY ile osteoporoz oranları ise sırasıyla \%17,5, \%49,3 ve \%90 idi. ORAl ile hastaların \%54'ünde düşük, \%38,7'ünde orta ve \%7,3'ünde yüksek risk belirlendi. Düşük orta ve yüksek risk grupların KMY ile osteoporoz oranları ise sırasıyla \%20,3, \%45,2 ve \%79,5 idi. OSIRIS ile hastaların $\% 66,3$ 'ünde düşük, \%27,9'ünde orta ve $\% 5,8$ 'sinde yüksek risk belirlendi. Düşük, orta ve yüksek risk grupların KMY ile osteoporoz oranları ise sırasıyla $\% 21,9, \% 52,7$ ve $\% 87,1$ idi (Tablo 4). Tüm risk indekslerinde, risk kategorisi yüksek olgularda KMY ile saptanan osteoporoz oranı da yüksek olarak bulunmuştur.

Risk indekslerinin performansları değerlendirildiğinde; L1-L4 vertebrada osteoporozu belirlemede duyarlılı̆̆ ve seçiciliği en yüksek indeksler sırası ile SCORE ve OST olarak bulundu. PTD ve
NTD değerlerine bakıldığında yine SCORE ve OST indekslerinin performansının daha iyi olduğu izlendi. FRAX (KMY'li olmayan) performansı değerlendirildiğinde FRAX-H ve FRAX-M nin seçiciliğinin yüksek olduğu izlendi (Tablo 5). Femur boynunda duyarlık ve seçicilik açısından OSIRIS ve OST daha iyi bulundu. PTD

\section{Tablo 1. Olguların demografik özellikleri.}

\begin{tabular}{|c|c|}
\hline Değişkenler & $n=537$ \\
\hline Yaş (yil) (ortalama $\pm s s)$ & $59,5 \pm 8,6$ \\
\hline Boy uzunluğu (cm) (ortalama $\pm s s)$ & $153,9 \pm 6,5$ \\
\hline 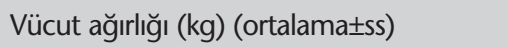 & $71,4 \pm 12,0$ \\
\hline Vücut kitle indeksi $\left(\mathrm{kg} / \mathrm{m}^{2}\right)$ (ortalama $\left.\pm \mathrm{ss}\right)$ & $30,1 \pm 4,8$ \\
\hline Menarş yaşı (yıl) (ortalama $\pm s s)$ & $13,8 \pm 1,4$ \\
\hline Menopoz yaşı (yıl) (ortalama $\pm s s)$ & $49,0 \pm 3,4$ \\
\hline Menopoz süresi (yıl) (ortalama \pm ss) & $13,8 \pm 1,4$ \\
\hline Östrojen tedavisi (n (\%)) & $48(8,9)$ \\
\hline Romatoid artrit (n (\%)) & $14(2,6)$ \\
\hline Düşük şiddetli kırık öyküsü (n (\%)) & $53(9,9)$ \\
\hline
\end{tabular}

\section{Tablo 2. Osteoporoz risk indekslerinin skorlaması.}

\begin{tabular}{|c|c|c|c|}
\hline OST & >1 (düşük risk) & -3 ile 1 (orta risk) & $<-3$ (yüksek risk) \\
\hline \multicolumn{4}{|l|}{0,2 x (vücut ağırlığı (kg) - yaş) } \\
\hline SCORE & <7 (düşük risk) & 7-15 (orta risk) & $>15$ (yüksek risk) \\
\hline Siyah ırk dışında bir ırka sahip olmak & & & +5 \\
\hline Romatoid artrit & & & +4 \\
\hline 45 yaşından sonra travmatik olmayan kırık & & & + 4 (her kırık için), (maksimum 12) \\
\hline Yaş & & & + 3 (her bir dekat için) \\
\hline Östrojen tedavisi & & & + 1 (hiç kullanmamışsa) \\
\hline Vücut ağırlığı & & & - 1 (her 4,5 kg için) \\
\hline ORAI & $<9$ (düşük risk) & 9-17 (orta risk) & $>17$ (yüksek risk) \\
\hline Yaş $>75$ & & & +15 \\
\hline Yaş 65-74 yıl & & & +9 \\
\hline Yaş 55-64 yıl & & & +5 \\
\hline Vücut ağırlığı $<60$ kg & & & +9 \\
\hline Vücut ağırlığı 60-70 kg & & & +3 \\
\hline Östrojen tedavisi & & & + 2 (şu anda kullanmıyorsa) \\
\hline OSIRIS & >1 (düşük risk) & -3 ile 1 (orta risk) & $<-3$ (yüksek risk) \\
\hline Vücut ağılığı (kg) & & & $+0,2 \times$ vücut ağırlığı \\
\hline Yaş (yıl) & & & $-0,2 \times$ yaş \\
\hline Düşük travmalı kırık öyküsü & & & -2 \\
\hline Östrojen tedavisi & & & +2 \\
\hline
\end{tabular}

OST (Osteoporosis Screening Tool-Osteoporoz Tarama Aracı)

SCORE (Simple Calculated Osteoporosis Risk Estimation-Basit Hesaplanan Osteoporoz Risk Tahmini)

ORAI (Osteoporosis Risk Assessment Instrument-Osteoporoz Risk Değerlendirme Aracı)

OSIRIS (Osteoporosis Index of Risk-Osteoporoz Risk İndeksi) 


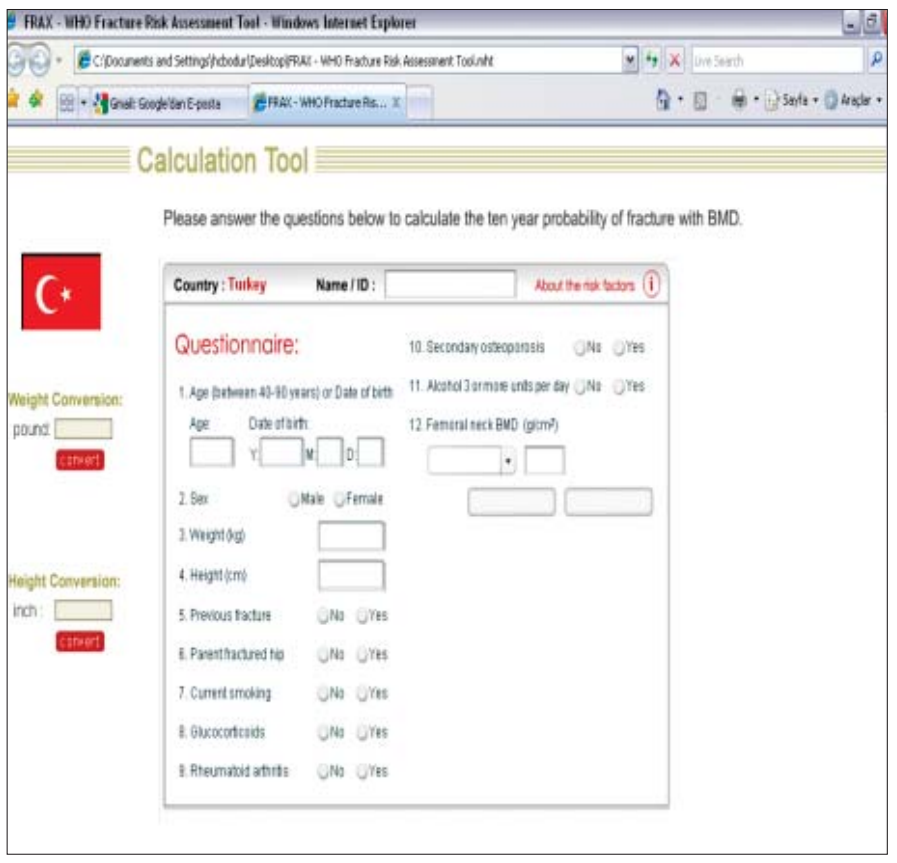

Şekil 1. FRAX algoritması.

ve NTD açısından FRAX-H'nin en etkin olduğu tespit edildi. (Tablo 6). Genel (L1-L4 ve/veya femur boynu) olarak, duyarlık ve seçicilik açısından en etkili indeksler yine SCORE ve OST idi (Tablo 7).

Tablo 8'de risk indeksleri ve FRAX algoritmasının KMY'de osteoporozu öngörmedeki etkinlikleri verilmiştir. Buna göre OST $(p=0,015)$ ve SCORE'un $(p=0,019)$ lomber bölgede tahmin değeri yüksek bulunmuştur. Femur boynunda ise FRAX-H anlamlı olarak üstün idi $(p=0,009)$. Femur boynu osteoporozu tahmininde OST indeksinin performansı için $p$ değeri 0,054 olarak bulunmuştur. Genel değerlendirmede ise, L1-L4 vertebrada olduğu gibi en belirleyici indeks OST olarak bulunmuştur $(p=0,006)$ bunu SCORE izlemekteydi $(p=0,046)$.

İkinci aşamada duyarlılığı, seçiciliği, PTD ve NTD'i daha iyi olan OST, SCORE ve FRAX-H için çoklu lojistik regresyon analizi ile performans değerlendirildi; L1-L4 omurga için OST'nin yanına SCORE da eklendiğinde duyarlılık düzeyi tek değişkenli analiz sonucuna göre azalırken seçicilik düzeyinde artış saptanmıştır. Başka bir ifade ile OST'nin yanına SCORE eklendiğinde KMD yönünden normal olan olguların daha iyi seçilebileceği söylenebilir. Femur boynu için FRAX-H'nin yanına OST eklenmesinin tarama performansı üzerinde tek değişkenli analiz sonuçları üzerinde belirgin bir değiştirici etkisinin olmadığı görülmüştür. Femur boynu için OST'nin ek bir katkısının olmadığı ifade edilebilir. Genel değerlendirmede OST'nin yanına SCORE da eklendiğinde duyarlııı düzeyi tek değişkenli analiz sonucuna göre azalırken seçicilik düzeyinde artış saptanmıştır. Başka bir ifade ile OST'nin yanına SCORE eklendiğinde KMD yönünden normal olan olguların daha iyi seçilebileceği söylenebilir (Tablo 9).

\section{Tartışma}

Osteoporoz tanısında olası risk altındaki kadınların taranması ve buna bağlı olarak erken önlemlerin alınması, osteoporozun sağlık sistemine getirdiği yükün azaltılmasında en etkili yol olarak görülmektedir $(9,10)$. KMY ölçümü fraktür tahmini için referans yöntem olarak kabul edilir, ancak bu ölçüm maliyetli olup, erişimi kısıtlıdır. Çeşitli Avrupa ülkelerinde ölçüm yapılacak hastaların tespitinde belirgin kriterler olmaması nedeniyle KMY ölçümü geri ödeme kurumları tarafından karşılanmamaktadır. Düşük KMY ile ilişkili olarak klinik risk faktörlerinin kullanımına dayalı özellikle yüksek risk grubunda olan populasyonu bulmaya odaklanmış çalışmaların sayısı gittikçe artmaktadır $(11,12)$. Osteoporoz riskinin sınıflandırmasına yardımcı olmak üzere çeşitli tarama yöntemleri geliştirilmiştir. OST, SCORE, ORAI ve OSIRIS bunlar arasında yer almaktadır. Bu yöntemlerin amacı osteoporoz tanısı koymak değil KMY ölçümü yapılması gereken kişilerin tespit etmektir. Dolayısıyla hedef osteoporoz tanısı için yapılması gereken toplam KMY ölçüm sayısını azaltmaktır. Bu alanda yapılan son araştırmalar az değişkenli basit yöntemlerin kullanımını desteklemektedir (4). FRAX klinik risk faktörleri ve KMY kullanılarak 10 yıllık mutlak kırık riskini değerlendiren ve kırık riski yüksek kişileri saptamak için kullanılan web tabanlı bir algoritmadır. FRAX da yukarıda sayılan tarama araçlarına benzer şekilde kırık riskini verir (8).

Çalışmamızda olgularda DXA ile saptanan osteoporoz oranı L1-L4 vertebra bölgesinde \%31,8 femur boynunda \%40,2 ve L1L4 vertebra ve/veya femur boynunda (en az bir bölgede) ise \%34,3 idi. Tüm risk indekslerinde risk kategorileri yüksek olgularda DXA ile saptanan osteoporoz oranı yüksekti. Bu sonuç risk indekslerinin klinik pratikte kullanımının önemini ortaya koymaktadır.

L1-L4 vertebrada osteoporozu belirlemede duyarlılığı ve seçiciliği en yüksek indeksler sırası ile SCORE (duyarlılık \%71,3 ve seçicilik \%66,4) ve OST (duyarlılık \%66,7 ve seçicilik \%69,4) olarak bulundu. Femur boynunda üstün bulunan indeksler OSIRIS (duyarlılık \%74,6 ve seçicilik \%74,5) ve OST (duyarlılık \%84,7 ve seçicilik \%62,2) idi. Genel olarak, duyarlık ve seçicilik açısından en etkili indeksler yine SCORE (duyarlılık \%72,3 ve seçicilik $\% 68,3$ ) ve OST (duyarlılık \%68,5 ve seçicilik \%71,7) idi. Risk indekslerinin performanslarını değerlendiren çeşitli araştırmalar mevcuttur. OST indeksinin Asyalı kadınlarda femur boynunda osteoporoz riskini belirleme performansını değerlendiren bir çalışmada duyarlıık \%91, seçicilik \%45 olarak bildirilmiştir (13). Yine beyaz kadınlarda yapılan bir diğer çalışmada femur boynu osteoporozunu saptamada duyarlık \%92, seçicilik \%37, lomber vertebrada ise duyarlık \%85 ve seçicilik \%37 bulunmuştur (4). Chan ve ark. (14) Çinli kadınlarda OST'nin osteoporoz riski taşıyan postmenopozal kadınların belirlenmesinde etkili bir indeks olduğu sonucuna varmıştır. SCORE indeksinin performansını belirlemeye yönelik yapılan çalışmalarda duyarlık \%90-98, seçicilik ise \%13-51 arasında değişmektedir (15-17). Lydick ve ark. (18) çalışmasında eşik değeri 6 kabul etmiş, duyarlıı̆̆ı \%89, seçiciliği ise \%50 bulmuş ve bu indeksin kullanımının hastaları KMY incelemesine göndermede \%30 azalma sağladığı belirtilmiştir. Bir başka çalışmada ise femur boynu osteoporozunu saptamada duyarlılığın yaklaşık \%90 olabilmesi için eşik değerin 7 ve üzerinde olması gerektiği vurgulanmıştır (19). Biz de çalışmamızda eşik değeri 7 olarak kabul ettik ve genel olarak osteoporoz açısından SCORE duyarlıığını \%72,3 ve seçiciliğini \%68,3 PTD'si \%54,3, NTD'si ise $\% 82,5$ olarak saptadık. Karkucak ve ark. (20), eşik değer 6 olarak alındığında, duyarlılığı \%86,7, seçiciliği \%59,1, PTD'si \%63 ve NTD'si \%82,5 olarak bulmuşlardır. Bu çalışmada 45-49 yaş 
aralığında ise duyarlılık \%85, seçicilik \%100 olarak saptanmıştır. Araştırmacılar indeksin femurdaki etkinliğinin, lomber bölgeye göre düşük olduğunu ancak basit, ekonomik ve pratik bir test olması nedeniyle hastanın kliniği ile birlikte değerlendirilerek kullanılabileceğini öne sürmüşlerdir. Ben Sedrine (17) 65 yaş üstünde SCORE indeksinin performansının düşük olduğunu bildirmiştir. Yine Ungar ve ark. (15) SCORE indeksinin performansının 50-59 yaşları arasında yüksek olup, eşik değerin \%0'li yaşlar için 6, 60'ı yaşlar için 8 olarak alınmasının uygun olacağını belirtmişlerdir. Bizim çalışmamızda hastaların önemli bir bölümü $(\% 75,5) 65$ yaş altında olduğundan indeksler için yaşa

Tablo 3. Olguların KMY ölçüm bölgelerindeki osteopeni ve osteoporoz dağılımı.

\begin{tabular}{|lc|}
\hline Değişkenler & $\mathrm{n}=537$ \\
\hline L1-L4 vertebra KMY ( $\mathrm{( \% )})$ & $129(24)$ \\
Normal & $237(44,1)$ \\
Osteopeni & $171(31,8)$ \\
Osteoporoz & \\
Femur boynu KMY (n (\%)) & $216(40,2)$ \\
Normal & $262(48,8)$ \\
Osteopeni & $59(11)$ \\
Osteoporoz & \\
Genel ( $\mathrm{n}(\%))$ & $100(18,6)$ \\
Normal & $253(47,1)$ \\
Osteopeni & $184(34,3)$ \\
\hline Osteoporoz & \\
\hline Genel: En az bir bölgede osteoporozu olanların toplamı \\
\hline
\end{tabular}

göre değerlendirme yapılmadı. ORAI indeksi ile yapılan bir çalışmada eşik değer 9 olarak alındığında femur boynu ya da lomber vertebra T-skoru $\leq 2$ olan kadınları belirlemede indeksin duyarlığı ve seçiciliği sırası ile $\% 90$ ve \%45 olarak saptanmıştır (6). OSIRIS indeksi ile yapılan bir diğer çalışmada ise eşik değer 1 olarak alındığında, femur boynu ya da lomber vertebra osteoporozu saptamada duyarlık \%78,5, seçicilik ise \%51,4 olarak tespit edilmiştir (7). Günaydın ve ark.'nın (21) çalışmasında OST, SCORE, ORAI ve OSIRIS indekslerinin femur boynu osteoporozunu saptamada duyarlılıkları \%72-86, seçicilikleri \%38-54 arasında iken, bu değerler lomber vertebra osteoporozu için sırasıyla \%58-73 ve \%38-55 idi. Osteoporotik kadınları saptamada dört indeksin performanslarının benzer olduğu ve femur boynu osteoporozunu saptamada lomber bölgeye göre daha üstün oldukları bildirilmiştir. Delialioğlu ve ark. (22) OST, NOF, OPERA ve AMMEB indekslerini değerlendiren çalışmalarında OST'nin femur boynu için duyarlıı̆̆ı, seçiciliği, PKD ve NKD'lerini sırasıyla \%80, \%68, \%28 ve \%95 olarak bildirmiştir. L2-L4 vertebra için bu oranlar sırasıyla \%54, \%76, \%54 ve \%76 bulunmuştur. AMMEB'in femur boynu için duyarlılığı, seçiciliği, PKD ve NKD'lerini sırasıyla \%80, \%68, \%27 ve \%93 iken L2-L4 vertebrada bu oranlar iken \%60, \%73, \%54 idi. Bu veriler sonucunda femur boynu osteoporozunu saptamada OST ve AMMEB'in yüksek duyarlılığa sahip olduğu, lomber ostoporozu saptamada ise, dört indeksin de duyarlılıklarının düşük olduğu tespit edilmiştir . Literatürde FRAX ile yapılan çalışma ise çok azdır.

Çalışmamızda osteoporozu öngörmede lomber bölgede OST $(p=0,015)$ ve SCORE'un $(p=0,019)$, femur boynunda ise FRAX$H^{\prime}$ nin tahmin değeri anlamlı üstün bulunmuştur $(p=0,009)$. Genel değerlendirmede L1-L4 vertebrada olduğu gibi yine en belirleyici indeks OST olarak bulunmuştur $(p=0,006)$ bunu SCORE izlemiştir $(p=0,046)$. Sonuç olarak duyarlılığı, seçiciliği, PTD ve NTD'si daha üstün olan indeksler OST, SCORE ve FRAX- H olarak

Tablo 4. Indekslerin risk kategorileri ve KMY ölçüm bölgelerinde osteoporoz prevalansı.

\begin{tabular}{|c|c|c|c|c|}
\hline Risk Kategorileri & Toplam (\%) (n) & L1-L4 vertebra (\%) (n) & Femur boynu (\%) (n) & Lomber+Femur (\%) (n) \\
\hline \multicolumn{5}{|l|}{ OST } \\
\hline >1 (düşük risk) & $67,4(362 / 537)$ & $20,4(74 / 362)$ & $3,9(14 / 362)$ & $21,0(76 / 362)$ \\
\hline-3 ile 1 (orta risk) & $27,4(147 / 537)$ & $51,7(76 / 147)$ & $18,4(27 / 147)$ & $56,5(83 / 147)$ \\
\hline <-3 (yüksek risk) & $5,2(28 / 537)$ & $75,0(21 / 28)$ & $64,3(18 / 28)$ & $89,3(25 / 28)$ \\
\hline \multicolumn{5}{|l|}{ SCORE } \\
\hline <7 (düşük risk) & $54,4(292 / 537)$ & $16,8(49 / 292)$ & $2,7(8 / 292)$ & $17,5(51 / 292)$ \\
\hline 7-15 (orta risk) & $40,0(215 / 537)$ & $45,6(98 / 215)$ & $14,0(30 / 215)$ & $49,3(106 / 215)$ \\
\hline >15 (yüksek risk) & $5,6(30 / 537)$ & $80,0(24 / 30)$ & $70,0(21 / 30)$ & $90,0(27 / 30)$ \\
\hline \multicolumn{5}{|l|}{ ORAI } \\
\hline <9 (düşük risk) & $54,0(290 / 537)$ & $20,0(58 / 290)$ & $3,4(10 / 290)$ & $20,3(59 / 290)$ \\
\hline 9-17 (orta risk) & $38,7(208 / 537)$ & $41,8(87 / 208)$ & $13,5(28 / 208)$ & $45,2(94 / 208)$ \\
\hline$>17$ (yüksek risk) & $7,3(39 / 537)$ & $66,7(26 / 39)$ & $53,8(21 / 39)$ & $79,5(31 / 39)$ \\
\hline \multicolumn{5}{|l|}{ OSIRIS } \\
\hline >1 (düşük risk) & $66,3(356 / 537)$ & $21,3(76 / 356)$ & $3,9(14 / 356)$ & $21,9(78 / 356)$ \\
\hline-3 ile 1 (orta risk) & $27,9(150 / 537)$ & $48,0(72 / 150)$ & $16,7(25 / 150)$ & $52,7(79 / 150)$ \\
\hline$<-3$ (yüksek risk) & $5,8(31 / 537)$ & $74,2(23 / 31)$ & $64,5(20 / 31)$ & $87,1(27 / 31)$ \\
\hline
\end{tabular}

OST: Osteoporosis Screening Tool-Osteoporoz Tarama AracI, SCORE: Simple Calculated Osteoporosis Risk Estimation- Basit Hesaplanan Osteoporoz Risk Tahmini, ORAI: Osteoporosis Risk Assessment Instrument-Osteoporoz Risk Değerlendirme Aracı, OSIRIS: Osteoporosis Index of Risk-Osteoporoz Risk İndeksi 


\section{Tablo 5. Risk indekslerinin L2-L4 omurga kemik mineral yoğunluğu (T-skor $\leq-2,5$ eşik değerde) ölçüm bölgelerindeki performansları.}

\begin{tabular}{|c|c|c|c|c|c|}
\hline Risk Kategorileri & Duyarılık GP/(GP+YN) & Seçicilik GN/(GN+YP) & PTD GP/(GP+YP) & NTD GN/(YN+GN) & Doğruluk (GP+GN)/N \\
\hline OCT ( $<2$ veya $\geq 2)$ & $66,7(114 / 171)$ & $69,4(254 / 366)$ & $50,4(114 / 226)$ & $81,7(254 / 311)$ & $68,5(368 / 537)$ \\
\hline SCORE ( $\geq 7$ veya $<7$ ) & $71,3(122 / 171)$ & $66,4(243 / 366)$ & $49,8(122 / 245)$ & $83,2(243 / 292)$ & $68,0(365 / 537)$ \\
\hline ORAI $(\geq 8$ veya $<8)$ & $69,0(118 / 171)$ & $61,5(225 / 366)$ & $45,6(118 / 259)$ & $80,9(225 / 278)$ & $63,9(343 / 537)$ \\
\hline OSIRIS (<1 veya $\geq 1)$ & $50,3(86 / 171)$ & $78,1(286 / 366)$ & $51,8(86 / 166)$ & $77,1(286 / 371)$ & $69,3(372 / 537)$ \\
\hline FRAX T-M & $36,3(62 / 171)$ & $92,3(338 / 366)$ & $68,9(62 / 90)$ & $75,6(338 / 447)$ & $74,5(400 / 537)$ \\
\hline FRAX T-H & $35,1(60 / 171)$ & $94,3(345 / 366)$ & $74,1(60 / 81)$ & $75,7(345 / 456)$ & $75,4(405 / 537)$ \\
\hline FRAX M & $18,1(31 / 171)$ & $92,9(340 / 366)$ & $54,4(31 / 57)$ & $70,8(340 / 480)$ & $69,1(371 / 537)$ \\
\hline FRAX H & $22,2(38 / 171)$ & $93,4(342 / 366)$ & $61,3(38 / 62)$ & $72,0(342 / 475)$ & $70,8(380 / 537)$ \\
\hline \multicolumn{6}{|c|}{ 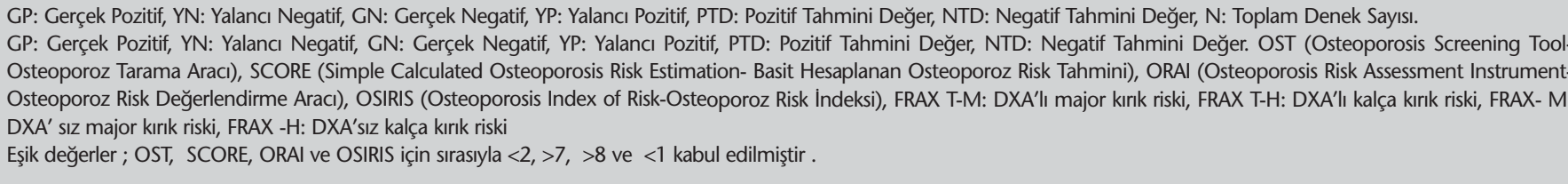 } \\
\hline
\end{tabular}

\section{Tablo 6. Risk indekslerinin femur boyun kemik mineral yoğunluğu (T-skor $\leq-2,5$ eşik değerde) ölçüm bölgelerindeki performansları.}

\begin{tabular}{|c|c|c|c|c|c|}
\hline Risk Kategorileri & Duyarlılık GP/(GP+YN) & Seçicilik GN/(GN+YP) & PTD GP/(GP+YP) & NTD GN/(YN+GN) & Doğruluk $(\mathrm{GP}+\mathrm{GN}) / \mathrm{N}$ \\
\hline OCT ( $<2$ veya $\geq 2$ ) & $84,7(50 / 59)$ & $63,2(302 / 478)$ & $22,1(50 / 226)$ & $97,1(302 / 311)$ & $65,5(352 / 537)$ \\
\hline SCORE $(\geq 7$ veya $<7$ ) & $86,4(51 / 59)$ & $59,4(284 / 478)$ & $20,8(51 / 245)$ & $97,3(284 / 292)$ & $62,4(335 / 537)$ \\
\hline ORAl $(\geq 8$ veya $<8)$ & $84,7(50 / 59)$ & $56,3(269 / 478)$ & $19,3(50 / 259)$ & $96,8(269 / 278)$ & $594(319 / 537)$ \\
\hline OSIRIS ( $<1$ veya $\geq 1$ ) & $74,6(44 / 59)$ & $74,5(356 / 478)$ & $26,5(44 / 166)$ & $96,0(356 / 371)$ & $74,5(400 / 537)$ \\
\hline FRAX T-M & $50,8(30 / 59)$ & $97,7(467 / 478)$ & $73,2(30 / 41)$ & $94,2(467 / 496)$ & $92,6(497 / 537)$ \\
\hline FRAX T-H & $71,2(42 / 59)$ & $97,9(468 / 478)$ & $80,8(42 / 52)$ & $96,5(468 / 485)$ & $95,0(510 / 537)$ \\
\hline FRAX M & $16,9(10 / 59)$ & $99,0(473 / 478)$ & $66,7(10 / 15)$ & $90,6(473 / 522)$ & $89,9(483 / 537)$ \\
\hline FRAX H & $28,8(17 / 59)$ & $98,7(472 / 478)$ & $73,9(17 / 23)$ & $91,8(472 / 514)$ & $91,1(489 / 537)$ \\
\hline \multicolumn{6}{|c|}{ 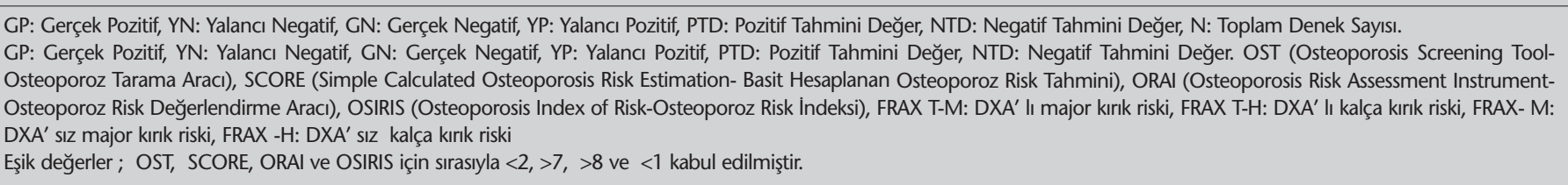 } \\
\hline
\end{tabular}

\section{Tablo 7. Risk indekslerinin genel olarak kemik mineral yoğunluğu (T-skor $\leq-2,5$ eşik değerde) ölçüm bölgelerindeki performansları.}

\begin{tabular}{|c|c|c|c|c|c|}
\hline Risk Kategorileri & Duyarlılık GP/(GP+YN) & Seçicilik GN/(GN+YP) & PTD GP/(GP+YP) & NTD GN/(YN+GN) & Doğruluk $(\mathrm{GP}+\mathrm{GN}) / \mathrm{N}$ \\
\hline OCT (<2 veya $\geq 2)$ & $68,5(126 / 184)$ & $71,7(253 / 353)$ & $55,8(126 / 226)$ & $81,4(253 / 311)$ & $70,6(379 / 537)$ \\
\hline SCORE $(\geq 7$ veya $<7)$ & $72,3(133 / 184)$ & $68,3(241 / 353)$ & $54,3(133 / 245)$ & $82,5(241 / 292)$ & $69,6(374 / 537)$ \\
\hline ORAl ( $\geq 8$ veya $<8)$ & $70,7(130 / 184)$ & $63,5(224 / 353)$ & $50,2(130 / 259)$ & $80,6(224 / 278)$ & $65,9(354 / 537)$ \\
\hline OSIRIS (<1 veya $\geq 1)$ & $52,7(97 / 184)$ & $80,5(284 / 353)$ & $58,4(97 / 166)$ & $76,5(284 / 371)$ & $70,9(381 / 537)$ \\
\hline FRAX T-M & $45,1(83 / 184)$ & $92,1(325 / 353)$ & $74,8(83 / 111)$ & $76,3(325 / 426)$ & $76,0(408 / 537)$ \\
\hline FRAX T-H & $46,7(86 / 184)$ & $92,4(326 / 353)$ & $76,1(86 / 113)$ & $76,9(326 / 424)$ & $76,7(412 / 537)$ \\
\hline FRAX M & $26,1(48 / 184)$ & $91,2(322 / 353)$ & $60,8(48 / 79)$ & $70,3(322 / 458)$ & $68,9(370 / 537)$ \\
\hline FRAX H & $31,5(58 / 184)$ & $89,5(316 / 353)$ & $61,1(58 / 95)$ & $71,5(316 / 442)$ & $69,6(374 / 537)$ \\
\hline \multicolumn{6}{|c|}{ 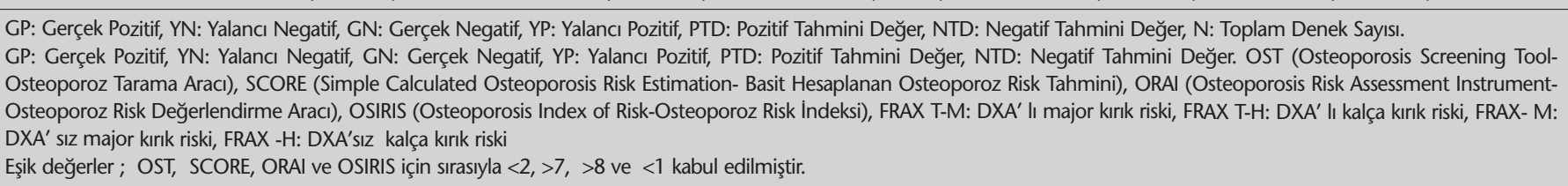 } \\
\hline
\end{tabular}


izlendi. L1-L4 omurgada ve genel olarak OST'nin yanına SCORE eklendiğinde KMD yönünden normal olan olguların daha iyi seçilebileceği bulduk. Ancak femur boynu için FRAX- H'nin yanına OST ilavesinin ek bir katkısı yoktu.

Bu basit, kolay ve herhangi bir ek maliyeti olmayan indekslerin kullanılması ile osteoporoz için düşük risk taşıyan hastaların saptanmasıyla gereksiz KMY tetkiki önlenebilir ve böylece maliyet düşürülebilir. Örneğin, çalışmamızda OST kullanıldığında kadınların \%67,4'ünün osteoporoz için düşük risk taşıdığı saptanmıştır. KMY çekimi ile bunların sadece \%3,9'unda femur boynunda osteoporoz tespit edilmiştir. Yine OST kullanıldığında kadınların \%32,6'sı orta ve yüksek risk grubunda yer almış, KMY çekimi ile bunların \%76'sında (45/59) femur boyun bölgesinde osteoporoz saptanmış, \%24'ünde KMY normal bulunmuştur. KMY çekimi açısından bakılacak olursa çalışmada toplam 537
KMY tetkiki yapılmış \%11'inde (59) femur boynunda osteoporoz tespit edilmiştir. Lomber bölgede; KMY ölçümü ile \%56,7 oranında osteoporoz saptanmış, \%43,2 olguda osteoporoz saptanmamıștır. Eğer OST kullanılarak risk grupları ayırt edilseydi orta ve yüksek risk grubunda olan toplam 175 (\%32,5) kadın, lomber bölge osteoporozu olan 97 kadını saptayabilmek amacı ile KMY ölçümüne gönderilecekti. Diğer taraftan düşük risk altında olduğu saptanan 362 olguya KMY çekilmeyecek ve bu grupta 74 osteoporotik kadın gözden kaçırılacaktı. Eğer OST kullanılarak risk grupları ayırt edilseydi orta ve yüksek risk grubunda olan toplam $175(\% 32,5)$ kadın, femur boynu osteoporozu olan 45 kadını saptayabilmek amacı ile KMY tetkikine gönderilecekti. Diğer taraftan düşük risk altında olduğu saptanan 362 olguya KMY çekilmeyecekti. Ancak bu grupta da 14 osteoporotik kadın gözden kaçırılacaktı. SCORE indeksi ile risk grupları ayırt edilse

Tablo 8. L2-L4 omurga, femur boyun ve genel olarak kemik mineral yoğunluğuna göre T-skor $\leq-2,5$ eşik değerini öngörmede risk indekslerinin çoklu etkilerinin incelenmesi.

\begin{tabular}{|c|c|c|c|c|c|c|}
\hline \multirow[t]{2}{*}{ KMY } & \multirow[t]{2}{*}{ Değişkenler } & \multirow[t]{2}{*}{ Odds Oranı } & \multirow[t]{2}{*}{ Wald } & \multirow[t]{2}{*}{ p değeri } & \multicolumn{2}{|c|}{ \%95 Güven Aralığı } \\
\hline & & & & & Alt Sınır & Üst Sınır \\
\hline \multirow[t]{6}{*}{ L2-L4 Omurga } & OCT $<2,0$ & 2,530 & 5,908 & 0,015 & 1,197 & 5,348 \\
\hline & Score $\geq 7,0$ & 2,217 & 5,541 & 0,019 & 1,143 & 4,303 \\
\hline & ORAI $>7,0$ & 0,906 & 0,080 & 0,777 & 0,458 & 1,792 \\
\hline & OSIRIS $<1,0$ & 0,788 & 0,563 & 0,453 & 0,423 & 1,468 \\
\hline & FRAX - M & 1,039 & 0,683 & 0,409 & 0,949 & 1,138 \\
\hline & FRAX - H & 1,055 & 0,331 & 0,565 & 0,879 & 1,266 \\
\hline \multirow[t]{6}{*}{ Femur Boyun } & OCT $<2,0$ & 3,944 & 3,707 & 0,054 & 0,976 & 15,942 \\
\hline & Score $\geq 7,0$ & 1,494 & 0,411 & 0,521 & 0,438 & 5,093 \\
\hline & ORAI >7,0 & 0,704 & 0,271 & 0,603 & 0,188 & 2,639 \\
\hline & OSIRIS $<1,0$ & 1,330 & 0,331 & 0,565 & 0,504 & 3,510 \\
\hline & FRAX - M & 0,985 & 0,065 & 0,799 & 0,878 & 1,105 \\
\hline & FRAX - H & 1,381 & 6,891 & 0,009 & 1,085 & 1,758 \\
\hline \multirow[t]{6}{*}{ Genel } & $\mathrm{OCT}<2,0$ & 2,873 & 7,702 & 0,006 & 1,363 & 6,052 \\
\hline & Score $\geq 7,0$ & 1,965 & 3,978 & 0,046 & 1,012 & 3,818 \\
\hline & ORAI $>7,0$ & 0,885 & 0,125 & 0,724 & 0,448 & 1,746 \\
\hline & OSIRIS $<1,0$ & 0,896 & 0,119 & 0,730 & 0,479 & 1,675 \\
\hline & FRAX - M & 1,022 & 0,199 & 0,656 & 0,929 & 1,125 \\
\hline & FRAX - H & 1,148 & 1,716 & 0,190 & 0,934 & 1,412 \\
\hline
\end{tabular}

Tablo 9. L2-L4 Omurga, femur boyun ve genel olarak kemik mineral yoğunluğuna göre T-skor $\leq-2,5$ eşik değerini öngörmede risk indekslerinin çoklu etkilerinin incelenmesi.

\begin{tabular}{|c|c|c|c|c|}
\hline Risk Kategorileri & Duyarlilık GP/(GP+YN) & Seçicilik GN/(GN+YP) & PTD GP/(GP+YP) & NTD GN/(YN+GN) \\
\hline \multicolumn{5}{|l|}{ L1-L4 vertebra } \\
\hline OST + SCORE & $63,2(108 / 171)$ & $74,3(272 / 366)$ & $53,5(108 / 202)$ & $81,2(272 / 335)$ \\
\hline \multicolumn{5}{|l|}{ Femur boynu } \\
\hline OST + FRAX H & $27,1(16 / 59)$ & $99,0(473 / 478)$ & $76,2(16 / 21)$ & $91,7(473 / 516)$ \\
\hline \multicolumn{5}{|l|}{ Genel } \\
\hline OST + SCORE & $64,7(119 / 184)$ & $76,5(270 / 353)$ & $58,9(119 / 202)$ & $80,6(270 / 335)$ \\
\hline
\end{tabular}


idi; 122 hastada lomber bölgede osteoporoz saptamak için 245 hastada KMY ölçümü yapılacaktı. SCORE'ye göre düşük risk grubunda olan 49 osteoporotik hasta ise gözden kaçacaktı. Femur boynu için ise 51 hastada osteoporoz saptanacak 8 hasta gözden kaçırılacaktı.

Sonuç olarak çalışmamızda duyarlılığı, seçiciliği, PTD ve NTD'si daha üstün olan indeksler OST, SCORE ve FRAX-H olarak izlendi. Ancak lomber bölgede gözden kaçan hasta oranı yeterince düşük değildi. Bu sonuç lomber bölge için belki de eşik değerlerin daha düşük tutulması ile aşılabilir. Bu yönde çalışmalar gereklidir. Ancak osteoporozda major morbidite ve mortalite sebebinin kalça osteoporozu ve kırıkları olduğu düşünülürse bu testlerin tarama testi olarak yararlı olacağı ileri sürülebilir.

\section{Çıkar Çatışması:}

Yazarlar herhangi bir çıkar çatışması bildirmemişlerdir.

\section{Kaynaklar}

1. Lips P; International Osteoporosis Foundation (IOF) Committee of Scientific Advisors. Invest in your bones: quality of life. Why prevent the first fracture? International Osteoporosis Foundation (IOF). Nyon (Switzerland): 2003.

2. Bartl R, Frisch B. Kemik mineral yoğunluğu (KMY): Çok önemli bir tanısal parametre. içinde: Tan AA, editor. Osteoporoz teşhis korunma tedavi. 1. Baskı Ankara, Ortadoğu Reklam Tanııım ve Yayıncılık A.Ş; 2006. s. 58-72.

3. Assessment of fracture risk and its application to screening for postmenopausal osteoporosis. Report of a WHO Study Group. World Health Organ Tech Rep Ser 1994;843:1-129.

4. Richy F, Gourlay M, Ross PD, Sen SS, Radican L, De Ceulaer F, et al. Validation and comparative evaluation of the osteoporosisselfassessment tool (OST) in a Caucasian population from Belgium. QJM 2004; $97: 39-46$

5. Caderette SM, Jaglal SB, Murray TM. Validation of the simple calculated osteoporosis risk estimation (SCORE) for patient selection for bone densitometry. Osteoporos Int 1999;10:85-90.

6. Cadarette SM, Jaglal SB, Kreiger N, Mclsaac WJ, Darlington GA, Tu JV. Development and validation of the Osteoporosis Risk Assessment Instrument to facilitate selection of women for bone densitometry. CMAJ 2000;162:1289-94.

7. Sedrine WB, Chevallier T, Zegels B, Kvasz A, Micheletti MC, Gelas B, et al. Development and assessment of the osteoporosis Index of Risk (OSIRIS) to facilitate selection of women for bone densitometry. Gynecol Endocrinol 2002; 16:245-50.
8. Kanis JA, Oden A, Johansson $H$, Borgström F, Ström O, McCloskey E. FRAX® and its applications to clinical practice. Bone 2009;44:734-43.

9. NIH Consensus Development Panel on Osteoporosis Prevention, Diagnosis, and Therapy. Osteoporosis prevention, diagnosis, and therapy. March 7-29, 2000: highlights of the conferance. South Med J 2001;94:569-73.

10. Johnel O. Advances in osteoporosis: better identification of risk factors can reduce morbidity and mortality. J Intern Med 1996;239:299-304.

11. Adami S, Giannini S, Giorgino R, Isaia G, Maggi S, Sinigaglia L, et al. The effect of age, weight, and lifestyle factors on calcaneal quantitative ultrasound: the ESOPO study. Osteoporos Int 2003;14:198-207.

12. Reginster J-Y, Kung $A$, Koh $L$, et al. A simple chart for evaluating risk of osteoporosis in Asian women based on the osteoporosis self-assessment tool for Asians (OSTA). Osteoporos Int 2002;13:30.

13. Koh LK, Sedrine WB, Torralba TP, Kung A, Fujiwara S, Chan SP, et al. A simple tool to identify asian women at increased risk of osteoporosis. Osteoporos Int 2001;12:699-705.

14. Chan SP, Teo CC, Ng SA, Goh N, Tun C, Deurenberg-Yap M. Validation of various osteoporosis risk indices in elderly Chinese females in Singapore. Osteoporosis Int 2006;17:1182-8.

15. Ungar W], Josse R, Lee S, Ryan N, Adachi R, Hanley D, et al. The Canadian SCORE questionnaire: optimizing the use of technology for low bone density assessment. Simple Calculated Osteoporosis Risk Estimate. J Clin Densitom 2000;3:269-80.

16. von Muhlen D, Visby Lunde A, Barrett-Connor E, Bettencourt R. Evaluation of the simple calculated osteoporosis risk estimation (SCORE) in older Caucasian women: the Rancho Bernardo study. Osteoporos Int 1999:10:79-84.

17. Ben Sedrine W, Devogelaer JP, Kaufman JM, Goemaere S, Depresseux G, Zegels $\mathrm{B}$, et al. Evaluation of the simple calculated osteoporosis risk estimation (SCORE) in a sample of white women from Belgium. Bone 2001;29:374-80.

18. Lydick E, Cook K, Turpin J, Melton M, Stine R, Byrnes C. Development and validation of a simple questionnaire to facilitate identification of women likely to have low bone density. Am J Manag Care 1998;4:37-48.

19. Geusens P, Hochberg MC, van der Voort DI, Pols H, van der Klift M, Siris $\mathrm{E}$, et al. Performance of risk indices for identifying low bone density in postmenopausal women. Mayo Clin Proc 2002;77:629-37.

20. Karkucak M, Capkin E, Kerimoglu S, Serdaroglu M, Topbas M, Yildiz H, et al. Performance of simple calculated osteoporosis risk estimation in a sample of women with suspected osteoporosis in the Turkish population. Rheumatol Int 2008;28:825-30.

21. Günaydın R, Karatepe AG, Kaya T, Karlıbaş U. Postmenopozal Osteoporozun tahmininde risk değerlendirme indekslerinin performansı. Romatizma 2007;22:48-54.

22. Ünsal Delialioğlu S, Kaya K, Özişler Z, Özel S. Risk değerlendirme indekslerinin postmenopozal osteoporozu tahmin etmedeki performansları. Osteoporoz Dünyasından 2009;15:21-5. 